\title{
Inhibition of Activated Protein C by Platelets
}

\author{
S. M. Jane, C. A. Mitchell, L. Hau, and H. H. Salem \\ Department of Medicine, Monash Medical School, Prahran, Victoria, Australia
}

\begin{abstract}
Activated protein C (APC), an anticoagulant that acts by inactivating Factors Va and VIIIa, is dependent on a suitable surface for its action. In this study we examined the ability of human platelets to provide this surface and support APC-mediated anticoagulant effects. The activity of APC was examined in three systems: the Factor Xa recalcification time of $\mathrm{Al}(\mathrm{OH})_{3}$ adsorbed plasma, studies of thrombin generation in recalcified plasma, and assessment of the rate of inactivation of purified Factor Va. In comparison with phospholipid, intact platelets required significantly greater concentrations of $\mathrm{APC}$ to achieve a similar degree of anticoagulation. When washed platelet membranes were substituted for intact platelets, adequate support of APC was observed and the anticoagulant effect was similar to that obtained with phospholipid. Platelet releasate obtained by stimulation of platelets with thrombin and epinephrine contained an inhibitor that interfered with the ability of phospholipid and washed platelet membranes to catalyze the anticoagulant effects of APC. A noncompetitive inhibition was suggested by Dixon plot analysis of the interaction between platelet releasate and APC. The activity of the platelet APC inhibitor was immediate and was not enhanced by heparin, distinguishing it from the circulating protein $\mathrm{C}$ inhibitor. The presence of this inhibitor in the platelet and its release with platelet stimulation emphasizes the procoagulant role of this cell.
\end{abstract}

\section{Introduction}

Protein $\mathrm{C}$ is a vitamin $\mathrm{K}$-dependent serine protease that is activated by thrombin in the presence of thrombomodulin or, to a lesser extent, Factor Va (1-4). Activated protein C (APC) ${ }^{1}$ is a potent anticoagulant that inactivates the coagulation cofactors Va and VIIIa in a calcium- and phospholipid-dependent reaction (5). The effects of APC are also enhanced by a second protein, protein $\mathrm{S}$, which is thought to increase the affinity of APC to the phospholipid surface (6). Studies using unstimulated bovine platelets have demonstrated that APC had little or no influence on the rate of Factor $\mathrm{Va}$ inactivation in the absence of protein $S(7)$.

The in vivo regulation of APC activity is poorly understood. Unlike other serine proteases in the coagulation system it is not inactivated by antithrombin III (8). A specific APC

Address correspondence to Dr. S. M. Jane, Department of Medicine, Alfred Hospital, Commercial Rd., Prahran, Victoria, Australia.

Received for publication 30 November 1987 and in revised form 2 August 1988.

1. Abbreviations used in this paper: APC, activated protein C.

J. Clin. Invest.

(c) The American Society for Clinical Investigation, Inc.

$0021-9738 / 89 / 01 / 222 / 05 \$ 2.00$

Volume 83, January 1989, 222-226 inhibitor was first suggested by Malar and Griffin (9) and subsequently purified and characterized by Suzuki et al. (10). This inhibitor covalently complexes with APC in a reaction accelerated 10-30-fold by large concentrations of heparin. The prolonged incubation time required for the neutralization of the amidolytic and anticoagulant activity of APC by this inhibitor suggests that it is probably not the sole physiological regulator of APC.

In this study we report the presence of an APC inhibitor in human platelets that, when released, interferes with the ability of platelet-mediated support of APC.

\section{Methods}

All chemicals were purchased from Sigma Chemical Co. (St. Louis, MO) except the following: $\mathrm{NaCl}, \mathrm{CaCl}_{2}, \mathrm{Na}_{2} \mathrm{HPO}_{4}, \mathrm{NaH}_{2} \mathrm{PO}_{4} \cdot 2 \mathrm{H}_{2} \mathrm{O}$, and EDTA (Ajax Chemical Co., Sydney, Australia); $\mathrm{KH}_{2} \mathrm{PO} 4$ and D-glucose (Mallinckrodt, Inc., St. Louis, MO); SDS (Pierce Chemical Co., Rockford, IL); acrylamide (Bio-Rad Laboratories, Richmond, CA); and H-D-Phe-pipecolyl-Arg-p-nitroanilide (S2238; Kabi AB, Stockholm, Sweden).

The assay buffer referred to throughout this manuscript was 20 $\mathrm{mM}$ Tris, $\mathrm{pH} 7.4$, containing $0.15 \mathrm{M} \mathrm{NaCl}$ and $0.1 \%$ gelatin. The platelet washing buffer, pH 6.5 , contained $0.113 \mathrm{M} \mathrm{NaCl}, 4.3 \mathrm{mM}$ $\mathrm{K}_{2} \mathrm{HPO}_{4}, 4.3 \mathrm{mM} \mathrm{Na}_{2} \mathrm{HPO}_{4}, 24.3 \mathrm{mM} \mathrm{NaH}_{2} \mathrm{PO}_{4} \cdot 2 \mathrm{H}_{2} \mathrm{O}$, and $5.5 \mathrm{mM}$ glucose. Coagulation factors were of human origin. Protein $\mathrm{C}$ (11), thrombin (12), antithrombin III (13), Factor V (14), prothrombin, Factor X (15), protein S (16), and thrombomodulin (17) were purified and activated as previously described. Protein $C(1 \mathrm{mg} / \mathrm{ml})$ was activated using $20 \mathrm{nM}$ thrombin in the presence of $15 \mathrm{nM}$ human throm-

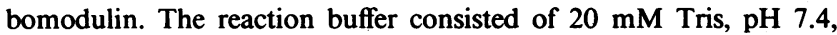
containing $0.15 \mathrm{M} \mathrm{NaCl}$ and $5 \mathrm{mM} \mathrm{CaCl}_{2}$. The mixture was incubated at $37^{\circ} \mathrm{C}$ and aliquots removed at various time points and assayed for protein $\mathrm{C}$ activation using the chromogenic substrate $\mathbf{S 2 2 3 8}$ as previously described (11). Protein $\mathrm{C}$ activation was usually completed after a 60 -min incubation, at which time antithrombin III $(150 \mu \mathrm{g} / \mathrm{ml})$ and heparin $(1 \mathrm{U} / \mathrm{ml})$ were added. The reaction was incubated for a further $10 \mathrm{~min}$ at $37^{\circ} \mathrm{C}$, allowing neutralization of all thrombin. The antithrombin III-heparin concentrations used in the highest concentration of APC were shown to have no effect on the results of coagulation studies.

Platelets were obtained from healthy volunteers. To minimize platelet activation the blood was collected in $5 \mathrm{mM}$ EDTA, $3.8 \%$

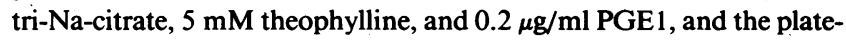
lets prepared and washed as previously described (18). The final platelet preparation was resuspended in assay buffer and counted in duplicate using a hemocytometer. The platelets were used within $4 \mathrm{~h}$ of blood collection and unless otherwise specified were not subjected to any further activation before use in coagulation studies. However, since some degree of activation is virtually inevitable during preparation, nonactivated platelets cannot be assumed to be completely inactive. For the separation of the membranes from the cytosol, $2 \mathrm{ml}$ of washed platelets $\left(5 \times 10^{7} / \mathrm{ml}\right)$ were disrupted by three cycles of freezethawing and the suspension subjected to maximum intensity sonication (Labsonic 15110, ultrasonic cell disrupter; B. Braun, Melsungen A. G., West Germany) for $45 \mathrm{~s}$ at $4^{\circ} \mathrm{C}$. The disrupted platelets were centrifuged at $100,000 \mathrm{~g}$ for $60 \mathrm{~min}$ at $4^{\circ} \mathrm{C}$ and the supernatant used as the cytosolic component. The membranes were washed twice in the platelet-washing buffer and resuspended in $2 \mathrm{ml}$ of assay buffer. 
Platelet aggregation was performed using $400 \mu \mathrm{l}$ of $5 \times 10^{7} / \mathrm{ml}$ platelets that were treated with $8 \times 10^{-6} \mathrm{M}$ epinephrine and $20 \mathrm{nM}$ thrombin. The platelets were stirred at $37^{\circ} \mathrm{C}$ in a Payton's dual channel aggregometer module at $250 \mathrm{rpm}$ for $10 \mathrm{~min}$.

Three methods were used to assess the anticoagulant activity of APC: the Factor Xa recalcification time of $\mathrm{Al}(\mathrm{OH})_{3}$ adsorbed plasma (19), thrombin generation in recalcified plasma, and studies of the rate of inactivation of purified Factor Va. The phospholipid used in these studies was of two types: a commercial rabbit brain phospholipid reagent (platelin, General Diagnostics, Morris Plains, NJ), or homogeneous single-lamellar phospholipid vesicles consisting of $75 \%$ phosphatidylcholine and 25\% phosphatidylserine (PCPS) prepared as described (20).

Thrombin generation was assessed by incubating $100 \mu$ l plasma, 20 $\mu \mathrm{M}$ phospholipid, and/or $5 \times 10^{7} / \mathrm{ml}$ platelets, and varying concentrations of APC. The volume of the reaction was adjusted to $600 \mu \mathrm{l}$ using the assay buffer, and thrombin formation was initiated by the addition of $8 \mathrm{mM} \mathrm{Ca}^{++}$. At various time points $40-\mu \mathrm{l}$ aliquots were removed and the amount of thrombin formed assayed by measuring the rate of hydrolysis of the chromogenic substrate $\mathbf{S 2 2 3 8}$. The amidolytic reaction $(600 \mu \mathrm{l})$ contained $0.2 \mathrm{mM} \mathrm{S} 2238$ in assay buffer. The concentration of thrombin formed was determined by reference to a standard curve constructed using known amounts of thrombin.

Factor $\mathrm{V}$ was assayed using a purified component assay as described (21).

\section{Results}

In preliminary experiments we investigated if platelets could substitute for phospholipid as a surface for the mediation of the anticoagulant activity of APC. These studies were performed using washed platelets (as detailed in Methods) that were not subjected to any specific activation before use in coagulation assays. Initial experiments were performed using a Factor $\mathrm{X}_{\mathrm{a}}$ recalcification time of $\mathrm{Al}(\mathrm{OH})_{3}$ adsorbed plasma and the concentration of platelets was adjusted to give a clotting time, that in the absence of APC, was comparable to that obtained using $20 \mu \mathrm{M}$ phospholipid. In this assay, APC (20 $\mathrm{nM}$ ) resulted in a 100-s prolongation of the clotting time in the presence of either the commercial phospholipid reagent or the homogeneous PCPS vesicles. When platelets were substituted for phospholipid, the same concentration of APC produced an insignificant prolongation of the clotting time $(2 \mathrm{~s})$. Furthermore, platelets, when added to the phospholipid containing reaction, negated the effects of $\mathrm{APC}$, and the prolongation of the clotting time was similar to that seen using platelets alone (Fig. 1). These results suggested that platelets failed to provide an adequate surface for APC anticoagulant activity and in-

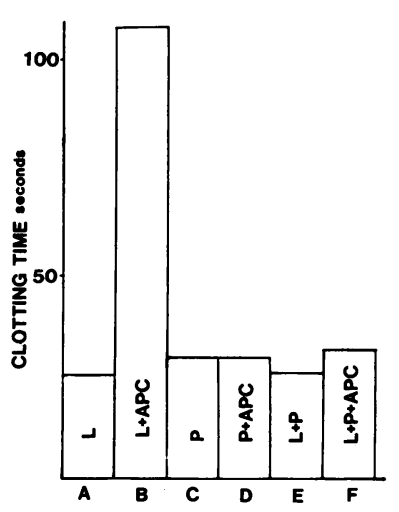

Figure 1. Comparison of platelet and lipid support of APC anticoagulant activity. APC anticoagulant activity was measured using a Factor Xa recalcification time of $\mathrm{AL}(\mathrm{OH})^{3}$-adsorbed plasma as described in Methods. Baseline clotting studies in the absence of APC were performed using $20 \mu \mathrm{M}$ phospholipid $(A), 5 \times 10^{7} / \mathrm{ml}$ platelets $(C)$, or $20 \mu \mathrm{M}$ phospholipid and $5 \times 10^{7} / \mathrm{ml}$ platelets $(E)$. The effect of APC (20 $\mathrm{nM})$ in each system is shown in $B, D$, and $F$, respectively. stead inhibited the effects of APC observed in the presence of phospholipids.

To validate the results obtained using the Factor Xa recalcification time, studies of the effects of APC on thrombin formation in recalcified plasma were performed. The advantage of this system is that it quantitates the rate of thrombin generation in contrast to the Factor Xa recalcification time which is an end point assay. The concentration of platelets used in these studies was adjusted to yield rates of thrombin formation comparable to those obtained using phospholipid. As in previous assays the platelets were not specifically activated before the experiments. The results are shown in Fig. 2, $A-C$. As seen, 2 $\mathrm{nM}$ APC caused a marked reduction in thrombin generation in the presence of the lipid reagent (Fig. $2 A$ ). On the other hand, platelets nullified the activity of APC irrespective of the presence or absence of phospholipid (Fig. 2, $B-C$ ).

The effect of increasing concentrations of APC on the inhibitory potential of intact platelets is shown in Fig. 3. Using 5 $\times 10^{7} / \mathrm{ml}$ platelets, a 15 -fold greater concentration of APC was necessary to produce inhibition in thrombin generation comparable to that achieved by APC and phospholipid.

The observation that the platelet offered poor support for the effects of APC was confirmed by studies of the rate of inactivation of purified Factor Va (Fig. 4). In these experiments APC (0.125 nM) and phospholipid rapidly inactivated Factor $\mathrm{Va}$ with a rate of $1.7 \mathrm{U} / \mathrm{min}$. In contrast, when 5 $\times 10^{7} / \mathrm{ml}$ platelets were substituted for the lipid, the proteo-
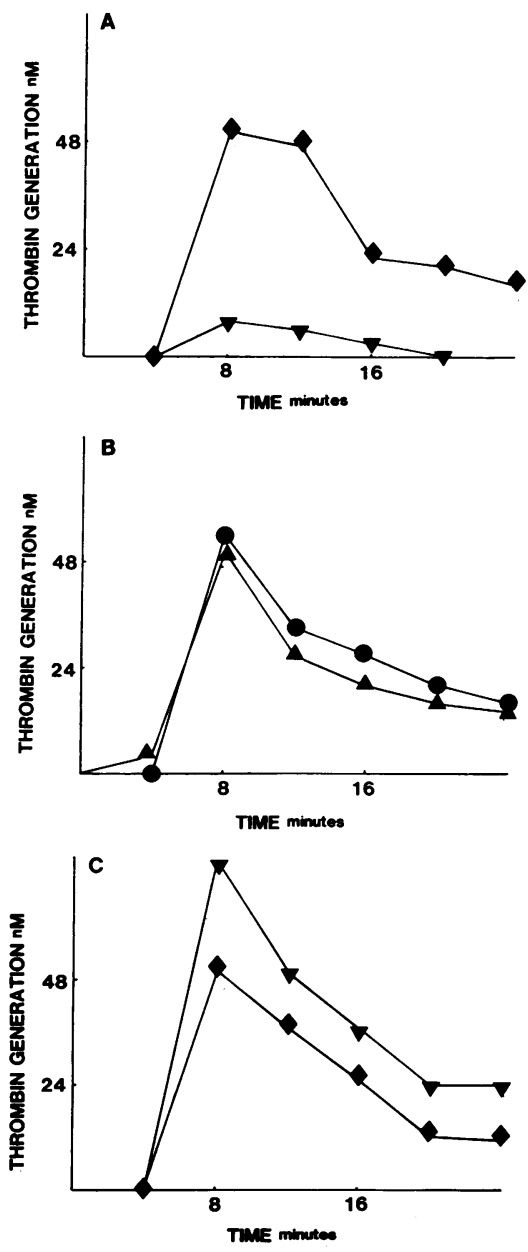

Figure 2. (A) Effect of APC and phospholipid on thrombin generation in recalcified plasma. Thrombin generation in platelet-poor plasma was assessed using 20 $\mu \mathrm{M}$ phospholipid in the presence $(\nabla)$ or absence $(\diamond)$ of 2 nM APC. Thrombin formation was monitored using the chromogenic substrate $\mathbf{S 2 2 3 8}$ as detailed in Methods. $(B)$ Effect of APC and platelets on thrombin generation in recalcified plasma.

Studies of thrombin generation were performed using $5 \times 10^{7} /$ $\mathrm{ml}$ platelets in the absence $(\bullet)$ or presence (ム) of 2 nM APC. Other details are as described for $A$. (C) Effect of APC on thrombin generation in the presence of phospholipid $(20 \mu \mathrm{M})$ and 5 $\times 10^{7} / \mathrm{ml}$ platelets. Thrombin generation was assessed as for $A$ in the presence $(\bullet)$ or $a b-$ sence $(\boldsymbol{\nabla})$ of $2 \mathrm{nM}$ APC. 


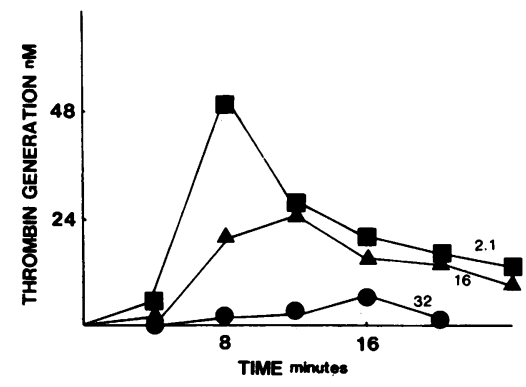

Figure 3. Thrombin generation in the presence of platelets: the effects of increasing concentrations of APC. Thrombin generation in plasma was performed using $5 \times 10^{7} / \mathrm{ml}$ platelets and APC at a concentration of $2 \mathrm{nM}(\boldsymbol{\omega})$, $16 \mathrm{nM}(\Delta)$, or $32 \mathrm{nM}(\bullet)$

lytic effects of APC in concentrations up to $0.5 \mathrm{nM}$ were negated and Factor Va remained stable. In the absence of platelets or phospholipid $0.5 \mathrm{nM}$ APC slowly inactivated Factor Va at a rate of $0.28 \mathrm{U} / \mathrm{min}$.

To determine whether APC was inhibited by a surface or internalized component of platelets, membrane and cytosol fractions were prepared as described in Methods. The time course of Factor Va inactivation by $0.125 \mathrm{nM}$ APC and platelet membranes demonstrated rapid cleavage of Factor Va with a rate comparable to that achieved with phospholipid. The recombination of platelet cytosol with the membranes reproduced the APC inhibition observed in experiments where intact platelets were combined with phospholipids. These results suggest that the inhibitor is cytosolic and that washed platelet membranes can support APC-mediated Factor Va inactivation with rates comparable to those obtained with phospholipids.

We next examined the ability of the platelets to release this inhibitor. For this purpose $400 \mu \mathrm{l}$ of washed platelets $\left(5 \times 10^{7}\right.$ $\mathrm{ml}$ ) were aggregated as detailed in Methods. After irreversible aggregation the sample was subjected to centrifugation at $100,000 \mathrm{~g}$ for $25 \mathrm{~min}$. The releasate was tested for its APC-inhibitory activity in a Factor Va inactivation system and the results compared with those obtained using supernatant from nonactivated platelets. The rate of inactivation of Factor Va by $0.125 \mathrm{nM}$ APC and phospholipid was $1.7 \mathrm{U} / \mathrm{min}$ and was not significantly affected by the addition of supernatant from unactivated platelets (rate of inactivation $=1.65 \mathrm{U} / \mathrm{min}$ ). However, when the releasate of activated platelets was used a significant inhibition of the rate of Factor Va inactivation occurred (rate $=0.23 \mathrm{U} / \mathrm{min}$ ). These results, shown in Fig. 5, confirm

Figure 4. Comparison of platelets and phospholipid in their support of APC-mediated Factor Va inactivation. Reaction mixtures con-

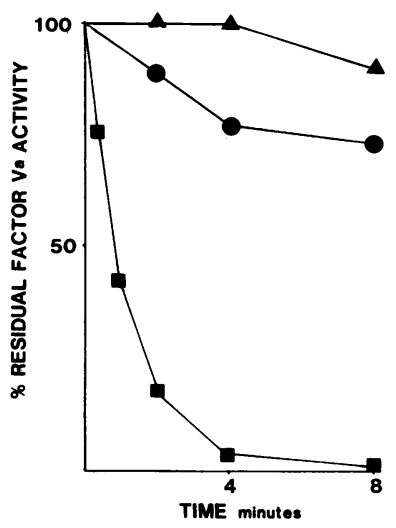
tained $15 \mathrm{nM}$ Factor Va, 0.125 nM APC, and $20 \mu \mathrm{M}$ phospholipid ( $)$; $15 \mathrm{nM}$ Factor $\mathrm{Va}, 0.5$ nM APC, and $5 \times 10^{7} / \mathrm{ml}$ platelets (৫); or $15 \mathrm{nM}$ Factor Va and 0.5 nM APC (•). The final volume of the reaction was adjusted to $70 \mu l$ using the assay buffer containing 5 $\mathrm{mM} \mathrm{Ca}{ }^{++}$. At the indicated time points, $2.5-\mu \mathrm{l}$ aliquots were removed and the residual Factor Va assayed as described (18). In the absence of APC, the Factor Va remained stable throughout the incubation.

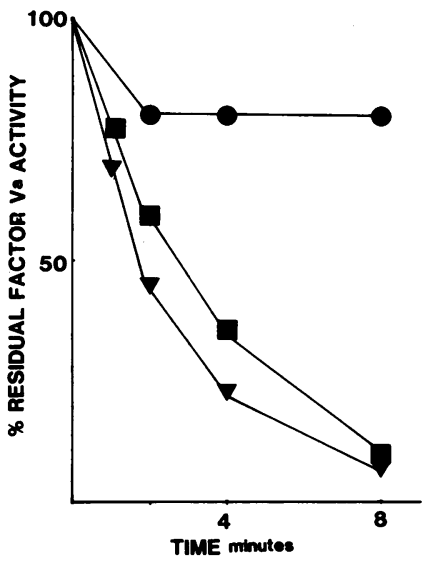

Figure 5. Effect of platelet releasate on the ability of phospholipid to support APC anticoagulant activity. Platelet releasate was prepared by treating $400 \mu \mathrm{l}$ of $5 \times 10^{7} / \mathrm{ml}$ platelets with $8 \times 10^{-6} \mathrm{M}$ epinephrine and $20 \mathrm{nM}$ thrombin. After aggregation hirudin $(1 \mathrm{U} / \mathrm{ml})$ was added and the platelets separated by centrifugation at $100,000 \mathrm{~g}$ for $25 \mathrm{~min}$. Factor $\mathrm{Va}$ inactivation studies were performed using $15 \mathrm{nM}$ Factor Va, $0.125 \mathrm{nM}$ APC, and $20 \mathrm{UM}$ phospholipid in the presence of $12 \mu \mathrm{l}$ of buffer $(\nabla)$; platelet releasate (๑); or supernatant from nonactivated platelets maintained in release inhibiting buffer, as described in Methods ( () ). Other assay conditions are as detailed for Fig. 4.

that the APC inhibitor is contained within the secretory granules of the platelets and is released upon platelet activation.

The effect of increasing concentrations of APC on the inhibitory potential of platelet releasate was assessed (Fig. 6). In the presence of phospholipid the rate of Factor Va inactivation increased linearly with increasing APC concentrations. Addition of platelet releasate to this system resulted in an eightfold increase in the amount of APC necessary to achieve comparable rates of Factor $\mathrm{Va}$ inactivation. The effects of the platelet releasate were also assessed using two concentrations of Factor $\mathrm{Va}$ in the presence of APC. A Dixon plot of these results (Fig. 7) suggests that platelet releasate is a reversible noncompetitive inhibitor of APC.

The inhibition of APC by platelet releasate was not enhanced by heparin in concentrations up to $5 \mathrm{U} / \mathrm{ml}$ and was not overcome by the addition of human protein $\mathrm{S}$ in concentrations up to $60 \mathrm{nM}$.

The inhibitor appears to be a protein since the activity was destroyed by heating at $100^{\circ} \mathrm{C}$ for $10 \mathrm{~min}$. It is not dialyzable using membranes with a cutoff of $10,000 \mathrm{D}$, and appears to be a high molecular weight molecule since it is excluded from a Sepharose 4B-CL gel filtration column, appearing in the void volume. The inhibitory activity is stable between $\mathrm{pH} 7$ and 9.5 . In buffers of $\mathrm{pH} 5$ or less the activity was lost. In other studies we attempted to directly demonstrate that the inhibitor binds to or modifies the structure of APC. Different approaches were

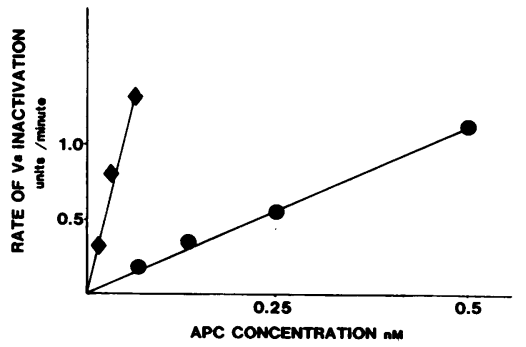

Figure 6. Inhibition of APC activity by platelet releasate. Platelet releasate was obtained as described in Fig. 5. The assay was performed using $15 \mathrm{nM}$ Factor Va, $20 \mu \mathrm{M}$ phospholipid, and the indicated concentrations of APC, in the presence of $12 \mu \mathrm{l}$ of buffer $(\bullet)$ or platelet releasate $(\bullet)$. Other assay conditions are as detailed in Fig. 5. Aliquots were assayed at 2, 4, and $8 \mathrm{~min}$ and the rate of Factor Va inactivation was calculated. 


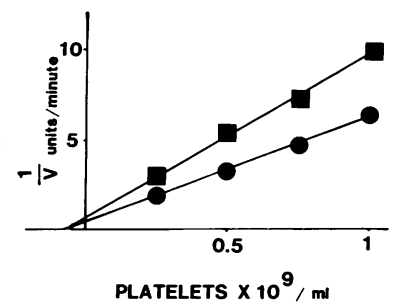

Figure 7. Dixon plot of APC inhibition by platelet releasate. Platelet releasate was prepared as detailed in Fig. 5 except that platelet concentrations were varied as indicated. Factor $\mathrm{Va}$ inactivation was performed using $0.0625 \mathrm{nM}$ APC, $20 \mu \mathrm{M}$ phospholipid, $12 \mu \mathrm{l}$ of platelet releasate, and Factor $\mathrm{Va}$ at $15 \mathrm{nM}(\bullet)$ or $7.5 \mathrm{nM}(\bullet)$

The volume of the reaction was adjusted to $70 \mu \mathrm{l}$ using the assay buffer containing $5 \mathrm{mM} \mathrm{Ca}^{++}$. The rate of Factor $\mathrm{Va}$ inactivation was calculated as detailed for Fig. 6.

used including immunoprecipitation, gel filtration chromatography, and agarose gel electrophoresis. Under no conditions were we able to demonstrate complex formation between APC and the putative inhibitor.

\section{Discussion}

An integral part of the hemostatic mechanism is the assembly of activation complexes on negatively charged surfaces. Traditionally, phospholipid has been used as the in vitro model of these surfaces. In vivo, platelets and endothelial cells catalyze several coagulation reactions, playing an essential role in accelerating thrombin formation $(12,22)$. These cells do not merely serve as a source of phospholipid, but provide high affinity binding sites essential for the interaction of coagulation proteins $(12,23)$. This is aptly demonstrated in studies of the prothrombinase complex, where platelets catalyze thrombin formation 20-fold faster than saturating concentrations of phospholipids (12). Similarly, endothelial cells possess specific binding sites for Factor IX/IXa which participates in Factor IXa-VIII activation of Factor X. The nature of this cellular receptor is unclear, although recent studies suggest that a membrane protein may be involved (23).

Studies on activated protein $C$ have highlighted the importance of a negatively charged phospholipid surface for maximal anticoagulant activity (5). The ability of platelets or endothelial cells to provide this support has so far not been fully delineated in man.

Our results confirm that the activity of APC is strongly dependent on the presence of phospholipids. We have demonstrated this using a Factor Xa recalcification time of $\mathrm{Al}(\mathrm{OH})_{3}$ adsorbed plasma, assays of thrombin generation in recalcified plasma, and studies of the rate of inactivation of purified Factor Va. Surprisingly, intact platelets failed to effectively support the activity of APC in all three systems, and when mixed with phospholipid negated the effect of this surface.

Assays of thrombin formation in recalcified plasma indicate that in the presence of $5 \times 10^{7} / \mathrm{ml}$ platelets a 15 -fold greater concentration of APC was necessary to achieve an anticoagulant effect equivalent to that obtained using phospholipid. This same number of platelets was capable of generating thrombin in the absence of APC at rates comparable to those obtained using phospholipids.

In all these experiments the platelets were not specifically activated. However, it is likely that the washing procedure coupled with the early generation of thrombin during the coagulation reaction would have resulted in rapid platelet activation and the concomitant release of the APC inhibitor. This is supported by the observation that stimulation of the platelets with physiological agonists resulted in the release of APC-inhibitory activity, suggesting that it resides in the secretory granules. Dixon plot analysis of the interaction between the platelet APC-inhibitor and APC at two different concentrations of Factor Va suggested a noncompetitive inhibition. Meaningful calculation of the inhibitory constant for the reaction would be best performed when the inhibitor is purified.

Washed platelet membranes supported the anticoagulant activity of APC, with rates of Factor Va inactivation comparable to those obtained with phospholipid. These observations suggest that once released the APC inhibitor binds weakly to the platelet surface and becomes dislodged during the preparation of the membranes.

The fact that intact platelets inadequately support the effects of APC is not peculiar to man. In the bovine system Harris and Esmon (7) have reported that nonphysiological concentrations of APC $(5 \mu \mathrm{g} / \mathrm{ml})$ are required to saturate platelet binding sites. Furthermore, these high concentrations of APC resulted in rates of Factor $\mathrm{Va}$ inactivation significantly less than those obtained in the presence of phospholipids. These workers did not, however, explore the reasons for the difference between the activity of platelets and phospholipid.

The platelet APC inhibitor reported in our study differs from the circulating protein $\mathrm{C}$ inhibitor characterized by $\mathrm{Su}$ zuki et al. (10). Inhibitory activity did not require preincubation with APC and was not enhanced by heparin. Initial characterization of the platelet APC inhibitor suggests that it is a protein of high molecular weight. However, until the purification of this inhibitor is complete further comparison with the plasma protein $\mathrm{C}$ inhibitor must remain speculative.

In conclusion, the results of this study demonstrate that platelets contain an inhibitor to APC that is released during platelet activation. Although platelets can offer an efficient surface for thrombin formation they are unable to effectively catalyze the activity of APC, and hence should be regarded as a predominantly procoagulant surface.

\section{Acknowledgments}

Dr. Jane is a National Health and Medical Research Council Ph.D. student, and this manuscript represents part of his thesis.

This study was supported by a program grant from the National Health and Medical Research Council of Australia.

\section{References}

1. Stenflo, J. 1976. A new vitamin K-dependent protein: purification from bovine plasma and preliminary characterisation. J. Biol. Chem. 251:355-363.

2. Kisiel, W., W. M. Canfield, L. H. Ericsson, and E. W. Davie. 1977. Anticoagulant properties of bovine plasma protein $C$ following activation by thrombin. Biochemistry 16:5824-5831.

3. Esmon, N. L., W. G. Owen, and C. T. Esmon. 1982. Isolation of a membrane bound cofactor for thrombin-catalyzed activation of protein C. J. Biol. Chem. 257:5532-5535.

4. Salem, H. H., G. J. Broze, J. P. Miletich, and P. W. Majerus. 1983. Human coagulation factor $\mathrm{Va}$ is a cofactor for the activation of protein C. Proc. Natl. Acad. Sci. USA. 80:1584-1588.

5. Walker, F. J., P. W. Sexton, and C. T. Esmon. 1979. The inhibition of blood coagulation by activated protein $C$ through the selective inactivation of activated Factor V. Biochim. Biophys. Acta. 571:333342. 
6. Walker, F. J. 1980. Regulation of activated protein C by a new protein. J. Biol. Chem. 255:5521-5524.

7. Harris, K. W., and C. T. Esmon. 1985. Protein S is required for bovine platelets to support activated protein $\mathrm{C}$ binding and activity. $J$. Biol. Chem. 260:2007-2010.

8. Kurachi, K., G. Schmer, M. A. Hermodson, D. C. Teller, and E. W. Davie. 1976. Characterisation of human, bovine, and horse antithrombin III. Biochemistry. 15:368-373.

9. Malar, R. A., and J. H. Griffin. 1980. Deficiency of protein C inhibitor in combined factor V/VIII deficiency disease. J. Clin. Invest. 66:1186-1189.

10. Suzuki, K., J. Nishioka, and S. Hashimoto. 1983. Protein C inhibitor: purification from human plasma and characterisation. $J$. Biol. Chem. 258:163-168.

11. Salem, H. H., N. L. Esmon, C. T. Esmon, and P. W. Majerus. 1984. Effect of thrombomodulin and Factor Va light chain on protein C activation in vitro. J. Clin. Invest. 73:968-972.

12. Miletich, J. P., C. M. Jackson, and P. W. Majerus. 1978. Properties of the factor Xa binding site on human platelets. J. Biol. Chem. 253:6908-6916.

13. Owen, W. G. 1975. Evidence for the formation of an ester between thrombin and heparin cofactor. Biochim. Biophys. Acta. 405:380-387.

14. Kane, W. H., and P. W. Majerus. 1981. Purification and characterisation of human coagulation factor V. J. Biol. Chem. 256:10021007.
15. Miletich, J. P., G. J. Broze, and P. W. Majerus. 1980. The synthesis of sulphated dextran beads for the isolation of human coagulation factors II, IX and X. Anal. Biochem. 105:304-310.

16. Dahlback, B. 1983. Purification of human vitamin K dependent protein $\mathrm{S}$ and its limited proteolysis by thrombin. Biochem. J. 209:2007-2010.

17. Salem, H. H., I. Maruyama, H. Ishii, and P. W. Majerus. 1984. Isolation and characterisation of thrombomodulin from human placenta. J. Biol. Chem. 259:12246-12251.

18. Baezinger, N. L., and P. W. Majerus. 1974. Isolation of human platelets and platelet membranes. Methods Enzymol. 31:149-155.

19. Mitchell, C. A., and H. H. Salem. 1987. Cleavage of protein S by a platelet membrane protease. J. Clin. Invest. 79:374-379.

20. Barenholz, Y., D. Gibbes, B. J. Litman, J. Goll, T. E. Thompson, and F. D. Carlson. 1977. A simple method for the preparation of homogeneous phospholipid vesicles. Biochemistry. 16:2806-2810.

21. Miletich, J. P., D. W. Majerus, and P. W. Majerus. 1978. Patients with congenital Factor $\mathrm{V}$ deficiency have decreased Factor Xa binding sites on their platelets. J. Clin. Invest. 62:824-831.

22. Rodgers, D. M., and M. A. Shuman. 1983. Prothrombin is activated on vascular endothelial cells by factor $\mathrm{Xa}$ and calcium. Proc. Natl. Acad. Sci. USA. 80:7001-7005.

23. Stern, D. M., P. P. Nawroth, W. Kisiel, G. Vehar, and C. T. Esmon. 1985. The binding of factor IXa to cultured bovine aortic endothelial cells: induction of a specific site in the presence of factors VIII and X. J. Biol. Chem. 260:6717-6722. 